\title{
Cost Accounting Implications For Corporate Wellness Programs
}

Paul J. Carruth, Southeastern Louisiana University, USA

Ann K. Carruth, Southeastern Louisiana University, USA

\begin{abstract}
The health of a company's employees is a considerable challenge for today's corporate executives. The reality of ever increasing healthcare costs has resulted in more companies now recognizing the value of health promotion through employee health and wellness programs. The potential return on investment is ultimately less turnover, less absenteeism, greater satisfaction in employment, better recruitment, and sustained success of companies. As the workplace is increasingly recognized as a potentially effective site for wellness intervention and employee health promotion, the challenges in offering these types of programs are apparent. The greatest challenge for employers is to maintain workplaces that provide health-promoting and sustaining policies, programs, and practices. Employees should have ready access to effective programs and services that protect their health, safety, and well-being. Wellness programs offered at the work site are one way for corporate America to meet this challenge.
\end{abstract}

Keywords: Corporate Wellness Programs, Accounting

\section{INTRODUCTION}

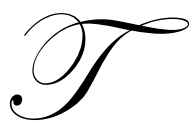

he health of a company's employees is a considerable challenge for today's corporate executives. As the reality sets in that employers have less ability to shift the cost of healthcare to the employees, more companies are now recognizing the value of health prevention and health protection through employee health and wellness programs. By keeping employees healthy, productivity in the workplace is sustained. Increasingly, national business organizations, as well as the National Institute for Occupational Safety, recognize not only the link between healthy workers and productivity, but also the ability of companies to control rising healthcare costs.

Healthcare costs comprise approximately 1.4 trillion dollars or $15 \%$ of the Gross Domestic Product (Center for Medicare and Medicaid Services, 2005). In 2002, businesses paid an average of $\$ 6,300$ per employee or an amount in excess of $42 \%$ of payroll expenses for medical benefits (United States Chamber of Commerce, 2004). Lack of employee wellness is very expensive for employers in terms of both costs of healthcare services as well as lost workplace productivity. Losses in worker productivity may be caused by employee job absences for illness, disability and healthcare provider visits.

Both employers and employees benefit from the provision of accessible comprehensive healthcare in the most cost effective and efficient methods possible. Extensive documentation indicates that for most healthcare situations, prevention and early access to care is more cost effective than treatment for chronic illnesses caused by lifestyle choices. Therefore, there has been a rapid growth in programs placing emphasis on wellness. The establishment of on-site healthcare services is an issue that has received increased interest in the health and wellness arena, especially among self-insured organizations.

The Steps to a Healthier U.S. Workforce initiative was launched in 2004 and was developed to encourage workplace safety and health programs that focus on preventing work-related illness, injury, and disability. In addition, this initiative promotes healthy living and lifestyles as a means to reduce and prevent chronic disease (Centers for Disease Control and Prevention, 2002). This initiative represents a paradigm shift that includes thinking 
about lifestyle behaviors, as well as workplace environmental issues, in considering the health of employees. Some of the lifestyle behaviors addressed include physical activities, nutrition, smoking, and substance abuse. These behaviors have a significant impact on people's health, yet are often not addressed by corporate companies through wellness programs. These lifestyle exposures contribute to many diseases including type 2 diabetes, hypertension, obesity, heart disease, stroke, and some forms of cancer. According to the Center for Disease Control and Prevention (Centers for Disease Control and Prevention, 2002), each year at least 300,000 people die from illnesses associated with obesity; 440,000 die from illnesses attributed to cigarette smoking; and 40\% of all deaths are caused by heart disease or stroke. Investments made in preventing acute and chronic illness experienced by the U.S. workforce can have a significant impact on the health-related productivity of American businesses.

\section{THE COST OF AN UNHEALTHY WORKFORCE}

Employers are losing millions of dollars each year as a direct result of increasing healthcare costs. According to the Kaiser family foundation and the health research and education trust, premiums for employer sponsored health insurance programs increased an average of 6\% in 2007 (http://www.kff.org). A workforce that is not healthy contributes to the rising costs of healthcare in the United States, as well as to a loss of productivity in the work place. Research has shown that employees with high risk factors have significantly higher healthcare expenditures than those with fewer risk factors associated with poor health outcomes. Specifically, employees who report depression, stress, high blood glucose levels, extremely high or low body weight, tobacco use, high blood pressure or sedentary lifestyles have been shown to result in greater healthcare cost for employers than other groups of individuals that do not have these risk factors (Goetzel, Anderson, Whitmer, Ozminkowski, Dunn, and Wasserman, 1998).

The cost of healthcare doubled from 1990-2001, and is projected to double again by 2012 (www.prevent.org). Employers are now examining the financial implications of the fact that many Americans suffer from at least one chronic condition such as arthritis, asthma, depression, diabetes, or heart disease. Each of these chronic diseases are very expensive to manage. Research indicates that $50 \%$ of healthcare expenditures are attributed to lifestyle preventable health behaviors. Heart disease and stroke are the most costly health conditions affecting employees (Goetzel, Jacobson, Aldana, Vardell, Yee, 1998).

The indirect costs associated with unhealthy employees can be two to three times the direct medical costs (Burton, et al. 2004; Edington, et al. 2003; Goetzel, et al., 2004; Pelletier, Boles, \& Lynch, 2004;). Productivity losses related to personal and family health problems has been estimated to cost U.S. employers $\$ 1,685$ per employee per year, or $\$ 225.8$ billion annually (Stewart, Ricci, Chee \& Morganstein, 2003). The U.S. Preventive Services Task Force supports employer coverage for clinical preventive services. In addition, the Advisory Committee on Immunization Practices recommends that employers increase coverage in order to promote the use of preventive services. By using wellness programs that emphasize total health and well-being, businesses can be more proactive in addressing the rising cost of healthcare (Clark, 2008).

\section{INVESTING IN EMPLOYEE HEALTH PROGRAMS}

According to a recent study by the Kaiser family foundation, employees are paying an increasing share of the cost for healthcare coverage. The average annual worker contributions for single and family coverage are \$694 and \$3281, respectively. These amounts are significantly higher than the amounts reported in 2006 (www.kff.org). Given that the costs of healthcare insurance have consistently outpaced inflation, employers are now beginning to examine their ability to address the problem of rising healthcare costs through prevention programs. Offering prevention programs is considered not only a sound business investment, but also is in line with the Center for Disease Control's Steps to a Healthier US Workforce initiative. Additionally, research to date indicates positive clinical and cost outcomes when companies provide individual risk reduction interventions for high-risk employees within the context of comprehensive worksite healthcare programs (Pelletier, 2001).

The trend is for companies to increasingly offer workplace wellness initiatives to address the healthcare needs of employees. Wellness programs not only address individual lifestyle choices, but also are expanding to include mental well-being. Increasing clinical evidence indicates that a lack of mental well-being can contribute to 
many chronic illnesses among employees. For example, some employers offer support groups, counseling, and rehabilitation services to support efforts at managing complicated chronic illnesses. The challenge for companies that offer these benefits is to get employees to take advantage of the services. Success in this area benefits not only the health of the individual, but also the overall culture of the work environment. One strategy used with increasing frequency is that of a "wellness coach" or "motivational employee health representative". While the names may sound creative, they represent a concept of ongoing contact with employees to motivate them to use wellness services to create an environment where a healthy workforce is the norm.

\section{APPROACHES TO WORKSITE EMPLOYEE HEALTH PROMOTION}

Companies that strive for a healthier workforce seek to provide healthcare services that will meet the needs of the greatest number of employees at the least cost. Employers now recognize that health behaviors impact life as well as work outcomes. Large work sites that have the resources to offer employees on-site centers with staff dedicated to providing worksite wellness programming have provided excellent settings to study the implications of various health conditions (Pratt, 2007).

Addressing employee health has many challenges. No one program will fit the needs of every employee. Many companies acknowledge the need to target the entire family, recognizing that behaviors that impact health are influenced by factors at home and work. Examples of employers engaging employees in wellness activities include companywide weight-loss contests, virtual communities using Avatars, and heart healthy computer-based programs. Many corporate programs include internet resources, surveys, health risk assessments, e-mail reminders, and internet-based newsletters. Nearly two-thirds of employers offer incentives to encourage employee participation. For example, an employee may get an insurance premium reduction upon completion of a health risk assessment. Cash or other in-kind incentives have also been provided. On the other hand, some employers penalize employees if they engage in unhealthy behaviors such as smoking, being overweight, or not managing high cholesterol by charging higher insurance premium rates. To address the issue that 15 percent of the population drives $85 \%$ of healthcare costs, the U.S. Department of Labor allows companies to reduce premiums up to $20 \%$ for employees who enroll in wellness programs. And in an extreme move to cut costs, some employers have stopped hiring anyone who smokes.

The majority of Americans, however, are employed in smaller organizations and their employers may not have the capacity to address worksite health promotion. In a recent survey of small businesses, the majority did not have significant work site health programs in place (McMahan, et al. 2001). In this survey, it was noted that over $16 \%$ of sites with between 100 and 500 employees had a nutrition program compared to $6.5 \%$ of work sites with less than 14 employees. This statistic highlights the fact that smaller worksites have less financial capacity to provide onsite wellness programs. When examining the types of programs that smaller workplaces can provide, it is noted that the majority of programs deal with emergency and disaster training, followed by hazardous materials training. At the bottom of ranked categories, $10 \%$ offer physical fitness programs, $8 \%$ diet and nutrition programs, and $8 \%$ weight management programs (McMahan, et al. 2001).

Building state of the art exercise facilities is not the only service employers can provide to invest in the health of workers. A recent national survey conducted by Partners for Prevention examined employer coverage for clinical preventive services. Clinical preventive services refer to healthcare interventions such as counseling, screening, or providing annual flu immunizations. These services are often provided in the early course of disease management, or in an effort to prevent the onset of disease to begin with. An example is providing counseling for an employee with chronic hypertension to motivate that employee to adhere to medication treatments. This in turn may result in slower progression of heart disease and other adverse health outcomes. Providing childhood immunizations, flu vaccinations, colorectal screening, tobacco cessation services, and alcohol problem prevention were rated as having high impact and value for small, medium, and large employers (Maciosek, 2006; U.S. Preventive Services Task Force, 1996). Unfortunately, many of the services are not currently covered under many company health benefit plans. However, preventive programs such as annual flu vaccinations create cost savings by reducing absenteeism by as much as $45 \%$ and may reduce other healthcare expenditures. 


\section{RETURN ON INVESTMENT (ROI) ON EMPLOYER SPONSORED HEALTHCARE PROGRAMS}

A review of research on worksite health promotion programs has consistently found that reductions in health risk and cost are associated with health promotion programs. However, traditional employee health programs can be labor-intensive and costly to implement (Pelletier, 1999; Aldana, 2001). Health education has been found to result in a significant reduction in risk factors. The effectiveness of workplace health promotion programs has been found to be effective in areas of high blood pressure control and smoking cessation. The economic benefits of health and education have been well-documented. Limited research exists that examines return on investments using health education as an intervention strategy. In a study of blue collar employees, individuals received a bimonthly health and fitness magazine to keep them informed of current health and wellness developments. Various topics were taught over lunch breaks suck as smoking cessation, fitness, weight control, lipid control, and stress management. Counseling was also provided. Researchers found a net difference of 11,726 fewer disability days over two years at program sites when compared to non-program sites. Savings due to lower disability costs provided a return of $\$ 2.05$ for every dollar invested in the program by the end of the second year (Bertera, 1990).

E-mail and web-based worksite programs have been used as a cost-effective approach to employee wellness programming. Cost savings have been documented when sequential e-mail messages to promote physical activity and healthy food intake among employed adults has been utilized. The internet spans geographic differences, sustains relationships, and provides links between and among employees and company resources available to promote health. Additionally, web access is available 24 hours a day seven days a week, and information can be customized for each individual participant. In 2005, a total of $74 \%$ of U.S. adults reported having web access, and this percentage is anticipated to increase over time. Many employers are promoting web-based programs such as the American Heart Association's Start program that promotes walking groups, as well as other web-based programs that provide tracking to monitor activity and weight loss. Another strategy used by companies is to provide healthier food choices in cafeterias, and in some cases to even charge employees less for healthier meals.

Work site employee programs often provide health risk assessment in order to understand the health status of the employees. The risk assessment includes comprehensive screenings that measure body mass index, blood pressure, cholesterol, risk for diabetes, asthma, heart disease, and other chronic conditions including back pain and injury. Some insurance companies offer discounts or incentives to employees for compliance with healthy lifestyles. On the other hand, in some states companies charge additional premiums for unhealthy behaviors such as smoking and obesity.

The concept of return on investments (ROI) can be applied to preventive care in the workplace setting. Return on investment is one of the most common measures of performance for a business or a segment of a business. Benefits of investments are often defined as cost reductions. The cost effectiveness analysis is the ratio of the net cost of an investment, in this case employee healthcare cost, to a defined health outcome (additional year of healthy work-life). A cost-effectiveness analysis of employee health examines long - term cost savings and long term outcomes. In order for an employer to feel that the return on investment is worthwhile, the current preventive cost must provide the benefit of adequate future cost savings.

Several studies provide evidence that employers get a good ROI on healthcare programs. Several systematic reviews have been done that generate evidence to support the cost savings of wellness programs. One review of 73 published studies of worksite health promotion programs shows an average $\$ 3.50$-to- $\$ 1$ savings-to-cost ratio in reduced absenteeism and healthcare cost (Aldana, 2001). And a more recent review of 42 published studies of worksite health promotion programs shows an average $28 \%$ reduction in sick leave absenteeism, an average $26 \%$ reduction in health costs, and an average $30 \%$ reduction in workers' compensation and disability management claims costs, with an average \$5.93-to-\$1 savings-to-cost ratio (Chapman, 2003).

Calculating the return on investment for wellness programs is difficult to measure and usually takes 3-5 years of data analysis. However, the potential return on investment is ultimately measured in terms of significant savings in healthcare cost, less turnover, greater job satisfaction among employees, and thus a more productive workforce. 


\section{SUMMARY AND CONCLUSIONS}

Today, employers are more actively investigating strategies designed to modify risk factors known to increase healthcare charges. These risk factors include employee physical inactivity, obesity, and smoking status. These risk factors have been strongly linked to a variety of long-term adverse health outcomes with significant costs not only to an individual firm, but also to society at large. To examine the relationship of modifiable health risks to subsequent healthcare costs, a cohort study of a stratified random sample of 5689 adults aged 40 years or older enrolled in a Minnesota health plan was conducted. This sample was used to compare and examine cost savings as it relates to modifiable health risks. Those who had never smoked and who had a BMI of $25 \mathrm{~kg} / \mathrm{m}^{2}$ or less and who participated in physical activity at least three days per week had a mean annual healthcare savings that reflected $49 \%$ lower costs than those physically inactive smokers with a BMI of $27.5 \mathrm{~kg} / \mathrm{m}^{2}$ (Pronk, Goodman, O'Connor, Martinson, 1999). The data from this study suggest that adverse health risk translates into significantly higher healthcare cost within a short period of time. Wellness programs seeking to minimize healthcare charges should consider strategic investments and interventions that effectively contribute to modifying adverse health risks among employees.

The idea of providing wellness programs within an employer based setting is prompted by the reality of the healthcare crisis in our nation today. While many may consider regular exercise to be sufficient in terms of preventive care, the reality is that preventive care must also target chronic disease. Hypertension, heart disease, cancer, diabetes, and obesity are all examples of long-term conditions and diseases that require ongoing monitoring and management. Providing clinical preventive services in a work setting for chronic diseases is one approach that has been recommended for improving productivity of the work force. Chronic disease is a serious problem in the United States. Approximately 125 million Americans of all ages reported having at least one chronic condition (U.S. Preventive Services Task Force, 1996). While this number reflects many individuals greater than 65, an estimated 58 million are between the ages of 18 and 65 . These individuals comprise the age range of most worker populations (Center on an Aging Society, 2004). Not only do chronic health conditions often lead to early death, they also limit daily activities for more than one out of 10 Americans, and account for at least $40 \%$ of the nation's annual healthcare expenditures (Cohen and Krauss, 1997).

Not all businesses have the ability to provide the same level of healthcare services as others. Some of the reasons that small businesses have difficulty in offering employee health plans are apparent. Small businesses often lack qualified staff and resources to implement, conduct, and evaluate employee health programs. The ability of an employer to offer employee health benefits is contingent not only on health insurance coverage but it is also a philosophy that supports employer based prevention programs and other types of wellness programs. The workplace is increasingly recognized as a potentially effective and efficient site for wellness intervention. Nevertheless, the challenges in offering these types of programs are apparent. The greatest challenge for employers is to provide workplaces that maintain health-promoting and sustaining policies, programs, and practices. For these efforts to be successful, employees must have ready access to effective programs and services that encourage their health, safety, and wellbeing. Ongoing research studies are providing evidence that wellness programs offered at the work site are now one of the most important ways that corporate America can meet this challenge.

\section{AUTHOR INFORMATION}

Paul J. Carruth, Ph.D., CPA is a Professor of Accounting at Southeastern Louisiana University.

Ann K. Carruth, DNS, RN is a Professor of Nursing and Graduate Co-ordinator at Southeastern Louisiana University.

\section{REFERENCES}

1. Aldana, SG. (2001). Financial impact of health promotion programs: a comprehensive review of the literature. Am J Health Promotion. 15(5):296-320; 7

2. Bertera, RL. (1990). The effects of workplace health promotion on absenteeism and employment costs in a large industrial population. AJPH, 80 (9), 1101-1105. 
3. Burton, WN, Pransky G, Conti DJ, Chen CY, Edington DW. (2004). The association of medical conditions and presenteeism. J Occup Environ Med. 46(6) suppl:S38-S45:

4. Center on an Aging Society. Workers Affected by Chronic Conditions. Issue Brief Number 7. June 2004. http://hpi.george- town.edu/agingsociety/pdfs/workplace.pdf. Accessed July 28, 2008.

5. Centers for Disease Control and Prevention (CDC), National Center for Chronic Disease Prevention and Health Promotion. Chronic Disease Prevention: Overview. www.cdc.gov/nccdphp/overview.htm. Accessed July 28, 2008.

6. In CDC. The Burden of Chronic Diseases and Their Risk Factors. National and State Perspectives. 2002.

7. Centers for Medicare and Medicaid Services. (2005). Table 1, National Healthcare Expenditures and Selected Economic Indicators, Levels, and Annual Percent Change: Selected Calendar Years 1990-2013 from www.cms.hhs.gov/statistics/nhe

8. Chapman, LS. (2003). Meta-evaluation of worksite health promotion economic return studies. The Art of HealthPromotion. 6(6):1-16.

9. Clark, AD. (2008). The new frontier of wellness. Benefits Quarterly. ${ }^{\text {nd }}$ Quarter. 24 (2), 23-28.

10. Cohen, JW and Krauss NA. (1997). Spending and service use among people with the fifteen most costly medical conditions, Health Affairs 22(2), March/April 2003: 129-138.

11. Edington, DW, Burton WN. Health and productivity (2003).In: McCunney, RJ: A Practical Approach to Occupational and Environmental Medicine. Philadelphia: Lippincott Williams \& Wilkins. 3rd ed.140-152; 2.

12. Goetzel, RZ, Long SR, Ozminkowski RJ, Hawkins K, Wang S, Lynch W. (2004). Health, absence, disability, and presenteeism cost estimates of certain physical and mental health conditions affecting U.S. Employers. $J$ Occup Environ Med. 46(4):398-412;

13. Goetzel, RZ, Anderson, D., Whitmer, R, Ozminkowski, RJ, Dunn, R \& Wasserman, J. (1998). The relationship between modifiable health risks and health care expenditures: An analysis of the Mult-Employer HERO health risk and cost database.

14. Goetzel, RZ. Jacobson, B.H, Aldana, S.G, Vardell, K., \& Yee, L (1998). Health care costs of worksite health promotion participants and non-participants. Journal of Occupational \& Environmental Medicine 40 (4), 341346.

15. Harper, SA, Fukuda K, Uyek TM, Cox NH, Bridges CB. (2004). Prevention and control of influenza. MMWR 53(RR06), May 28 2004: 1-40.

16. McMahan, S. Wells, M., Stokols, D., Phillips, K. and Clitheroe, H.C. (2001). Assessing health promotion in small business. American Journal of Health Studies, 17 (3), 120-128.

17. Maciosek, MV, Coffield, AB, Edwards, NM, Flottenmesch, TJ, Goodman, MJ, \& Solberg, LI. (2006). Priorities among effective clinical preventive services: results of a systematic review and analysis. American Journal of Preventive Medicine, July 31 (1) 52-61.

18. Report of the U.S. Preventive Services Task Force. Guide to Clinical Preventive Services: Second Edition (1996). http:// www.ncbi.nlm.nih.gov/books/bv.fcgi?rid=hstat3.part.19920. Accessed July 29, 2008.

19. Pelletier, KR. (1999). A review and analysis of the clinical and cost effectiveness studies of comprehensive health promotion and disease management programs at the worksite: 1995-1998 update. American Journal of Health Promotion July 13 (6) 333-345.

20. Pelletier, K.R. (2001). A review and analysis of the clinical and cost-effectiveness studies of comprehensive health promotion and disease management programs at the worksite: 1998-2000 update. American Journal of Health Promotion, 16(2) 107- and116.

21. Pelletier, B, Boles M, Lynch W. Change in health risks and work productivity over time. (2004). J Occup Environ Med. 46(7):746-754:

22. Pratt, CA. Lemon, S.C. Fernandez, I.D., Goetzel, R., Berefore, S. A., French, S.A., Stevens, V.J., Vogt, T.M., \& Webber, L.S. (2007). Design characteristics of worksite environmental interventions for obesity prevention. Obesity, 15 (9) 2171-2180.

23. Pronk, NP, Goodman MJ, O’Connor,PJ, \& Martinson, BC (1999). Relationship between modifiable health risk and short-term health care charges. JAMA, 282, 2235-2239.

24. Stewart, WF, Ricci JA, Chee E, Morganstein D. (2003). Lost productive work time costs from health conditions in the United States: results from the American productivity audit. J Occup Environ Med. 2003;45(12):1234124 ;

25. Kaiser Family Foundation (2007). (http://www.kff.org). Employer Health Benefits 2007 Annual Survey. Accessed July $28^{\text {th }}, 2008$.

26. United States Chamber of Commerce. (2004). Chamber survey shows worker benefits continue growth: Medical payments account for largest share of employee benefit costs. Washington, D. C. from http://www.uschamber.com 